\title{
Islam dan Budaya Banten
}

\author{
'Fahmi Irfani"
}

Abstract: Banten is one of the oldest centers of Islamic culture in Indonesia. Acculturation, assimilation, and diffusion represent something that is inevitable between Islam and local culture, thus showing a typical culture. This area is also known for its magical atmosphere of the place in search of knowledge kanuragan, supernatural power, as a form of debus culture reflection. Clerics, warlords kiyai, and jawara, are symbols of this region, and they occupy the position of the central figures in the social stratification of local communities. Kiyai and the Jawara of an honorary degree from the traditionalist Islamic groups are not only seen as religious figures, but also as charismatic community leaders. Their authority often exceed the power of the formal leader of an elite government. These exponents that characterize public offerings and bring to as different regions in the archipelago, mainly due to the unique culture, local tradition that integrate culture with Islam.

Keywords: Banten, Islam, kiyai, jawara, kultur, budaya lokal, magis, dan debus.

BERBICARA tentang Banten, maka setiap orang akan berasumsi bahwa daerah tersebut adalah tempat para ulama (kiyai) dan jawara. Stereotype tersebut muncul lantaran kuatnya Islam mengakar dalam

- Program Konsentrasi Sejarah dan Peradaban Islam Sekolah Pascasarjana Universitas Islam Negeri (UIN) Syarif Hidayatullah Jakarta. 
setiap individu masyarakatnya baik secara tradisi, kultural, maupun ritual. Selain itu daerah ini dikenal sebagai daerah magis tempat mencari ilmu kanuragan, kesaktian, debus dan sebagainya.

Banten merupakan daerah dengan penduduknya yang sangat heterogen. Heterogenitas ini bukan dimulai ketika Indonesia telah merdeka, akan tetapi telah ada sejak zaman Kesultanan (kerajaan) Islam Banten berdiri.

Perawakan orang Banten dikenal sebagai orang yang keras tetapi memiliki solidaritas yang tinggi. Kadangkala mereka tidak dapat membedakan mana yang harus dibela karena tingginya solidaritas mereka.

Di samping dikenal sebagai daerah kiyai, Banten dikenal sebagai tempatnya para jawara. MA Tihami mendeskripsikan dengan gamblang perbedaan makna dan peran antara kiyai, santri, dan jawara.

Dalam masyarakat Banten, kiyai adalah tokoh sentral dalam komunitas ini, sedangkan jawara dan santri adalah murid dari Kiyai. Perbedaan antara jawara dan santri terletak pada ketekunan mereka ketika berguru, santri lebih menekuni ilmu-ilmu keagamaan, sedangkan jawara lebih menekuni bidang yang terkait de-ngan pengolahan raga dan batin.

Eksponen-eksponen inilah yang mewarnai masyarakat Banten, dan menjadikannya sebagai daerah yang berbeda di Nusantara. Hal ini dikarenakan keunikan budaya, kultur tradisi lokal yang menyatu dengan Islam.

\section{Islam dan Banten}

Banten adalah salah satu propinsi di Indonesia yang terletak di bagian barat pulau Jawa. ${ }^{1}$ Banten sendiri dikenal sebagai wilayah perdagangan internasional.Banten yang terletak di ujung barat pulau Jawa, secara geografis merupakan daerah yang strategis untuk pelayaran dan perdagangan sejak masa pra Islam.

Banten sendiri terdiri atas empat kabupaten dan tiga kota, yaitu Kabupaten Serang, Pandeglang, Tangerang, dan Lebak, Kota Tangerang, Cilegon, dan Tangerang Selatan. Dari segi demo- 
grafi, Banten terdiri atas dua etnis, Sunda dan Jawa.

Sebagian besar penduduk yang mendiami wilayah ini menganut agama Islam sebagai kepercayaannya, walaupun masih terdapat sedikit yang menganut kepercayaan nenek moyang (orang Baduy).

Pada abad ke-16 $M$, Islam menyebar di wilayah Banten sampai mencapai puncaknya yang ditandai dengan berdirinya Kesultanan Banten Girang (1520-1820 M). Kesultanan Banten sendiri berdiri pada tahun 1552, yang diprakarsai oleh pangeran Sabakingking putra Sunan Gunung Djati, dengan melakukan pemberontakan dan menaklukkan Banten Girang. Atas perintah Sunan Gunung Djati, pusat pemerintahan Kesultanan Banten dipindahkan dari Banten Girang ke daerah Teluk Banten yang kemudian disebut Surosowan.

Kesultanan Banten diperintah oleh 19 orang Sultan, yaitu Maulana Hasanuddin panembahan Surosowan, sebagai Sultan pertama Kesultanan Banten Girang (15521570), Maulana Yusuf (1570-
1580), Maulana Muhammad (1580-1596), Sultan Abdul Mufakhir Mahmud (15961651), Sultan Ageng Tirtayasa (1651-1672), Sultan Abu Nasr Abdul Kahar (1672-1687), Sultan Abdul Fadhl (16871690), Sultan Abul Mahasin Zainal Abidin (1690-1733), Sultan Muhammad Syifa Zainul Arifin (1733-1750), Sultan Syarifuddin (1750-1752), Sultan Muhammad Wasi' (17521753), Sultan Muhammad Arif Zainul Asyikin (17531757), Sultan Abul Mufakhir (1773-1799), Sultan Muhyiddin (1799-1801), Sultan Muhammad Ishaq (1801-1802), Sultan Wakil Pangeran Natawijaya (1802-1803), Sultan Agiluddin (1803-1808), Sultan Wakil Pangeran Suramanggala (1808-1809), Sul$\tan$ Muhammad Syafiuddin (1809-1813), dan Sultan Muhammad Rafiuddin (18131820). ${ }^{2}$

Kesultanan Banten merupakan kesultanan yang egaliter dan terbuka bagi semua golongan dan agama. Hal ini dapat dilihat dengan hadirnya klenteng Tionghoa di dekat lingkungan Surosowan, yang didirikan pada masa Sultan 
Maulana Hasanuddin. Pembentukan Propinsi Banten merupakan suatu kemerdekaan bagi rakyat Banten, dengan beberapa alasan bahwa Banten telah mampu menghidupi dirinya sendiri, hingga masyarakat lupa bahwa kedaulatan Banten pada masa lalu bukan hanya dalam aspek teknologi dan ekonomi, tetapi juga masalah ideologi, lebih dari itu di mana Banten disatukan dengan satu keyakinan aqidah Islam.

Sebagai bekas kerajaan Islam, posisi ulama di wilayah ini tentu sangat kuat dan memiliki hierarki sosial yang signifikan di dalam struktur masyarakat Banten. Hal ini dikarenakan kedudukan ulama adalah perpanjangan tangan dari Sultan dalam proses Islamisasi di daerah pedesaan yang mendorong munculnya lembaga pesantren yang dipimpin oleh kiyai sebagai figur kepemimpinan.

Kiyai adalah guru yang mentrasformasi ilmu keislaman kepada santri-santrinya di pesantren. ${ }^{3}$ Kesultanan sendiri berdiri atas dasar Islam, baik dalam mengembangkan pengaruh maupun untuk memperkuat kedudukan dan kekuasaan Sultan. Hal ini menguntungkan kiyai yang memosisikanya sebagai pemimpin masyarakat.

Di Indonesia khususnya Banten, agama tidak hanya berpengaruh dalam kehidupan pribadi, tetapi juga berimplikasi dalam kehidupan masyarakat yang pada akhirnya hampir setiap sektor kehidupan tidak lepas dari justifikasi agama. Agama sebagai sumber utama sistem makna dalam kehidupan bermasyarakat yang berusaha memberikan jawaban terhadap permasalahan yang dihadapi manusia.

\section{Tarekat di Banten}

Pada masa Kesultanan Banten, ajaran Islam tumbuh subur di Banten, salah satu yang berkembang pesat dalam ajaran Islam saat itu adalah, menjamurnya tarekat di kalangan masyarakat. Banten sebagai salah satu pusat kebudayaan Islam di Indonesia dapat dengan mudah menerima pengaruh tarekat yang berkembang saat itu. Salah satu tarekat yang berkembang dengan subur di Banten 
adalah Tarekat Naqsyabandiyah. Menjamurnya ajaran tarekat di masyarakat Banten terjadi di masa Sultan Ageng Tirtayasa yang saat itu didampingi oleh Syaikh Yusuf alMaqassari, tokoh sufi yang berperan aktif dalam rangka pemurnian aqidah dan menjelaskan transendensi Tuhan atas ciptaan-Nya.

Sejarah panjang tarekat di Indonesia merupakan akulturasi antara ajaran agama Islam dengan tradisi budaya masyarakat lokal, yang diperkirakan berlangsung antara abad ke-8-18 M. Sebagian besar pengikut tarekat di Banten adalah para petani, mereka berkumpul mengikuti pengajian para syaikh. Tarekat di banten ternyata tidak semata sebagai gerakan keagamaan, tetapi juga sebagai gerakan sosial.

Menurut Martin Van Bruinessen, setidaknya Banten merupakan daerah yang terkenal dengan tingkat religiusitasnya yang tinggi dibandingkan dengan daerah lain di pulau Jawa. Pandangan Bruinessen ini paling tidak dapat dilihat bagaimana saat $\mathrm{Ta}-$ rekat Qadiriyah berkembang di Indonesia, seorang mursyid utamanya adalah Syaikh Abdul Karim Banten.

\section{Kiyai dan Jawara Simbol Masyarakat Banten}

Kiyai yang merupakan gelar ulama dari kelompok Islam tradisionalis tidak hanya dipandang sebagai tokoh agama, tetapi juga sebagai seorang pemimpin masyarakat yang kharismatik, kekuasaannya seringkali melebihi kekuasaan pemimpin formal elit pemerintahan. ${ }^{4}$

Kedudukan ini terus berlangsung walaupun Kesultanan Banten telah dihapus oleh H. W. Daendels pada tahun $1808 \mathrm{M}$ dan dikuasai oleh pemerintah kolonial $\mathrm{Be}$ landa. Kelestarin kepemimpinan kiyai sebagai tokoh masyarakat ini pun nampaknya didukung penuh oleh elemen masyarakat Banten. Hal ini dikarenakan kehadiran pemerintah kolonial Belanda sebagai penjajah yang telah menghapus sistem kesultanan dan mengambil alih kekuasaan.

Para tokoh kiyai inilah yang telah berhasil memimpin mobilisasi massa untuk memberontak, seperti halnya pem- 
berontakan petani Banten yang terjadi pada tahun 1888 dan pemberontakan komunis 1926 di Banten. ${ }^{5}$

Selain golongan ulama, di sisi lain terdapat golongan jawara yang tetap eksis sampai saat ini. Ada semacam pengakuan bahwa masyarakat Banten sebagiannya adalah orang-orang yang memiliki keberanian, kekuatan fisik, menguasai magis/mistik dan hal-hal lainnya yang menandai sosok kepribadian jawara.

Mereka yang mengakui akan adanya eksistensi para jawara tidak hanya masyarakat awam, termasuk kalangan akademisi yang pernah meneliti tentang Banten, seperti Sartono Kartodirdjo (1984) dan MA Tihami (1992).

Dengan pengakuan atas keperibadiannya itu tak heran kalau jawara dianggap sebagai pemimpin oleh segolongan tertentu masyarakat lokal. Para jawara tersebut turut berperan serta dengan para kiyai dalam memobilisasi pemberontakan-pemberontakan yang terjadi di Banten.

Eksistensi jawara di Banten tidak bisa lepas dari sosok kiyai, jawara adalah muridnya kiyai. Pada masa kolonial Belanda, jawara berfungsi sebagai tentara fisik yang bersama kiyai melakukan perlawanan terhadap tentara kolonial.

Tihami, dalam studinya menjelaskan bahwa kiyai memiliki dua varian murid, di antara muridnya tersebut ada yang memiliki kecenderungan bakat pada ilmu pengetahuan agama. Tetapi, adapula di antara muridnya yang memiliki kecenderungan ke arah perjuangan. Pada akhirnya murid yang cenderung pada ilmu agama disebut santri, sedangkan yang cenderung pada kekuatan fisik dan bernuansa magis adalah jawara. ${ }^{6}$ Maka dahulu posisi jawara merupakan pengawal para kiyai.

Pada masa-masa sulit jawara banyak membantu peran para kiyai terutama dalam hal keamanan dan ketertiban masyarakat. Kekuatan fisik, magis, dan kharisma para jawara diperoleh dari kiyai.

Lain halnya dengan Sartono Kartodirdjo, ia mendefinisikan kelompok jawara sebagai orang-orang yang tidak memiliki pekerjaan tetap dan sering melakukan perbuatan kriminal, dan cenderung digo- 
longkan ke dalam kelompok bandit sosial. Kedua golongan inilah yang memiliki peran ke: kuasan politik informal di daerah Banten, bahkan hal tersebut berlangsung sampai saat ini. Kedua golongan inilah yang disebut oleh Sartono Kartodirdjo sebagai golongan yang menembus batas-batas hierarki masyarakat Banten.'

Orang yang menyandang gelar kiyai dipandang sebagai ahli kebatinan, ahli hikmah, guru, dan pemimpin masyarakat yang berwibawa dan legitimated berdasarkan kepercayaan masyarakat.Oleh karena itu, gelar kiyai merupakan suatu tanda kehormatan dalam kedudukan sosial, bukanlah suatu gelar akademis yang diperoleh dalam pendidikan formal.

Sementara itu, jawara adalah sekelompok orang yang memiliki kekuatan fisik dan ilmu kesaktian, sehingga bagi sebagian orang dapat membangkitkan rasa hormat, kagum, takut, bahkan benci. Oleh karena itu, jawara dapat menjadi seorang tokoh kharismatik di Banten.

Berbeda halnya dengan para kiyai, peranan sosial ja- wara lebih cenderung kepada pengolahan kekuatan yang berujung kepada kekuasaan.

Hubungan simbiosis antara kedua kelompok itu kini seolah-olah terpisah karena pencitraa negatif para jawara. Peranan penguasaan politik di Banten tidak dapat dipisahkan dari kelompok jawara dan ulama. Kedua kelompok ini masih berpengaruh di dalam menentukan orientasi politik masyarakat di propinsi ujung bagian barat pulau Jawa ini.

Permasalahan selanjutnya yang terjadi adalah, pergeseran sosial yang menimbulkan pergesekan antara kedua belah pihak antara jawara dan ulama di dalam aspek politik.

Jika dahulu peranan tradisional yang sering dimainkan para jawara hanya sebatas menjadi jaro, guru silat dan satuan-satuan pengamanan (satpam). ${ }^{8}$ Maka berbeda pada masa ini terjadi pergeseran nilai dalam kelompok jawara itu sendiri, mereka adalah elit masyarakat karena di antara mereka ada yang menyibukkan diri di bidang ekonomi sebagai pengusaha, ada 
yang mendalami ilmu agama sebagai kiyai dan ada yang mengabdikan diri ke dunia politik sebagai birokrat.

\section{Kharisma Kepemimpinan Lokal}

Kharisma adalah gejala sosial yang terdapat ketika kebutuhan kuat muncul terhadap legitimasi otoritas. Sedangkan yang menentukan kebenaran kharisma adalah pengakuan pengikutnya. Pengakuan atau kepercayaan kepada tuntutan kekuatan gaib merupakan unsur integral dalam gejala kharisma. Kharisma adalah pengakuan terhadap suatu tuntutan sosial.

Gejala kharisma pada umumnya muncul pada waktu krisis, waktu perang, atau pada waktu kebudayaan saling bertentangan, terutama disebabkan masalah akulturasi. Kharisma selalu menyebabkan perubahan sosial, dan akan memunculkan suatu konflik antar pihak. ${ }^{9}$ Situasi masyarakat sebelum kharisma tidak pernah sama setelah kharisma.

Sedangkan dalam analisis Weber tentang kharisma, adalah suatu kualitas tertentu dalam kepribadian seseorang dengan mana dia dibedakan dari orang biasa dan diperlakukan sebagai seseorang yang memperoleh anugerah kekuasaan adikodrati, adimanusiawi, atau setidak-tidaknya kekuatan atau kualitas yang sangat luar biasa. ${ }^{10}$

Kekuatannya sedemikian rupa sehingga tidak terjangkau oleh orang biasa, tetapi dianggap sebagai berasal dari kayangan atau sebagai teladan dan atas dasar itu individu tersebut diperlakukan sebagai seorang pemimpin.

Menurut Weber, kharisma memainkan dua peranan yang sangat menonjol dalam kehidupan. Sebagai hal yang luar biasa, kharisma merupakan sumber kegoncangan dan pembaharuan, karena itu merupakan unsur strategis dalam perubahan sosial. Satu contoh yang mungkin juga representatif untuk menjelaskan kharisma dan kepemimpinan kha rismatik adalah kharisma yang dimiliki oleh para jawara dan ulama di Banten.

Pengelompokan kepemimpinan di dalam tubuh kelompok jawara sendiri menunjukkan adanya pengikut 
ataupun anak buah yang mengakui pimpinannya masingmasing. Setiap pemimpin diakui pengikutnya baik itu jawara kelompok pengusaha, kiyai ataupun politisi.

Meski pengelompokan pemimpin dan pengikut tersegmentasi, tetapi tetap ada koordinasi yang sangat kuat antar jawara karena mereka tergabung dalam sebuah organisasi bernama Persatuan Pendekar Persilatan dan Seni Budaya Banten Indonesia (PPPSBBI).

Ikatan inilah yang menjadi pemersatu para jawara. Patut diketahui bahwa ikatan emosional kelompok jawara sangat erat sekali antara guru dengan murid, antara beda perguruan yang memunculkan istilah satu guru satu ilmu.

Ikatan tersebut merupakan ikatan emosional kekeluargaan di dalam kelompok jawara, sehingga memunculkan rasa așabiah ${ }^{11}$ dan solidaritas tinggi antar jawara, sehingga mempermudah mereka dalam gerak politik.

Lain halnya dengan ulama, kelompok ini tidak terorganisir secara rapi walaupun terdapat kumpulan per- himpunan pesantren se-Banten, hal tersebut belum cukup merepresentasikan kelompok ulama dalam aspek politik.

Pergesekan antara kedua kelompok ini dalam tataran politik, disebabkan karena pada masa Orde Baru merupakan era yang merekonstruksi dan mreduksi peranan ulama dan jawara. Pada masa ini kelompok jawara dirangkul oleh para penguasa, sedangkan peranan ulama dalam hal politik di kempiskan.

Kekuasaan sendiri adalah kemungkinan seorang pelaku mewujudkan keinginannya di dalam suatu hubungan sosial yang ada, termasuk dengan kekuatan. ${ }^{12}$

Pada masa Orde Baru posisi ulama berhasil ditempatkan sebagai kelompok yang tergantung kepada pemerintah dan mesin politiknya. Sementara jawara diberi peran-peran ekonomi yang strategis di Banten, ${ }^{13}$ oleh karena itu perannya bergeser menjadi sebuah kekuatan ekonomi yang penting dan patron bagi pengusaha-pengusaha lokal.

Kini peranan jawara semakin penting setelah Banten 
menjadi propinsi sendiri. Peranan jawara tidak hanya dalam aspek ekonomi melainkan dalam percaturan politik lokal. Setiap pemilu nasional maupun pilkada yang bersifat lokal, para calon baik perorangan maupun partai politik tidak bisa melepaskan diri dari bekerja sama dengan para jawara.

Namun di pihak lain majunya elit jawara dalam kontes politik diikuti pula oleh kelompok ulama, hal inilah yang akan menjadi pergesekan dan persaingan ketokohan politik antara ulama dan jawara. Kedua kelompok inilah yang kini bisa beradu dan juga bekerjasama kembali dalam arena politik di Banten.

Dahulu jawara merupakan pengawal kiyai sedangkan saat ini jawara merupakan rival kiyai dalam tatanan pengaruh ketokohan dan kekuasaan dalam masyarakat Banten.

\section{Debus Banten}

Seni dan kesenian tidak terlepas dari perkembangan kebudayaan. Kebudayaan dan peradaban merupakan hasil usaha dan kemampuan ma- nusia dalam keinginannya untuk bertahan hidup. Sampai saat ini terdapat beberapa bentuk kesenian yang masih bertahan di Banten antara lain : seni bedug panjang, seni ubrug, seni patingtung, seni rudat, dan seni debus. Debus adalah salah satu kesenian Banten yang sampai saat ini masih bertahan dan lebih dikenal dibandingkan dengan bentuk-bentuk kesenian lainnya.

Kalaupun perjalanan sejarah debus kurang jelas, namun dari beberapa keterangan lisan para pemain debus, kesamaran sejarah tersebut dapat diselidiki. Jarangnya catatan tersebut karena rendahnya minat tulis menulis masyarakat Banten di masa lalu.

Ada beberapa asumsi yang mengatakan bahwa debus adalah permainan yang menunjukan kekebalan seseorang baik dari senjata api, tajam, api, dan sebagainya. Sementara ada asumsi lain yang menyatakan bahwa yang disebut dengan kesenian debus adalah kesenian yang menggunakan perangkat yang me- 
mang telah digunakan sejak zaman Kesultanan Banten.

Di sini dapat dipahami bahwa debus merupakan suatu jenis permainan untuk membuktikan kekebalan, dan alat yang digunakan disebut dabus, yaitu sebuah alat dari kayu yang ujungnya diberi besi tergantung yang runcing, serta kemampuan ajaib untuk tahan tidak luka memegang rantai yang dibakar hangus, praktik kekebalan diri dari pukulan dan tusukan. ${ }^{14}$

Padanan kata debuspun dapat dijumpai dalam beberapa literatur di luar Banten. Sementara di Aceh permainan seperti ini disebut dengan rapa'i atau daboih. Sementara di Sumatra Barat permainan sejenis ini disebut dabuih, yang merupakan kata dari bahasa minang berakar kata dari bahasa Arab yaitu dabbus yang berarti jarum tusuk.

Adapun kelompok debus-yang dibahas dalam tesis ini adalah kelompok debus yang berafiliasi kelompok dengan Tarekat Qodiriyah.

\section{Unsur-Unsur dalam Debus \\ Dalam permainan debus terdapat beberapa unsur yang}

saling terkait dan harus mendapat pehatian sendiri. Unsurunsur ini merupakan sesuatu yang penting dan saling terkait antara satu dan lainnya. Unsur-unsur tersebut adalah pemimpin atau syaikh debus, pemain, permainan, peralatan, pertunjukan, dan musik pengiring. Pemimpin debus adalah orang yang dituakan dalam kelompok tersebut.

Dalam permainan debus, seorang pemimpin atau syaikh debus merupakan unsur yang terpenting. Keberhasilan suatu permainan tergantung sejauhmana peranan dan keahlian seorang pemimpin dalam menjalankan tugasnya.

Seorang pemimpin tidak sebatas memimpin suatu pertunjukan, lebih dari itu ia adalah motivator yang membuat mereka berani melakukan atraksi.

Adapun anggota kelompok debus disebut dengan pemain debus. Biasanya pemain debus adalah orangorang yang telah mencapai usia dewasa, usia mereka antara 30-40 tahun, namun ada juga yang berusia 18-20 tahun. Dabus, merupakan sebu- 
tan untuk peralatan yang digunakan dalam permainan debus, yang berbentuk kayu silinder dengan rantai besi kecil di sekelilingnya dan terdapat paku besi di tengahtengahnya dengan ujungnya yang tajam.

Terdapat dua ukuran dari peralatan tersebut, yang besar dan kecil. Jika kelompok debus Cikande menggunakan alat yang ukurannya lebih kecil, sedangkan kelompok Ciruas dan Walantaka menggunakan dabus yang besar.

Permainan debus terbagi ke dalam dua teknik, pertama teknik A dan teknik B. teknik $A$, pemain debus memegang sebuah dabus kecil dan melakukan gerakan tarian serta menusukan dabus tersebut ke dalam tubuhnya sambil berseru "Allahu $A k$ bar".

Sedangkan teknik B, dabus yang digunakan berukuran besar dengan diangkat di atas pundaknya sambil menari, para pemain debus kemudian membentuk gerakan melingkar dan saling berhadapan. Pemain yang memegang dabus besar tersebut kemudian menusukan dabus tersebut ke dalam tubuhnya, sedangkan pemain yang lain memukul ujung dabus tersebut sambil berteriak "Syaikh al-Madad".

Selain jenis permainan tersebut, terdapat permainan yang lain seperti halnya membacok diri sendiri, membakar, menggoreng di atas kepala, menggelindingkan tubuh di atas paku, memakan pecahan kaca, dan sebagainya. Adapun unsur musik pengiring adalah sebagai pelengkap dan daya tarik permainan itu sendiri. ${ }^{15}$

Permainan debus itu sendiri biasanya dilakukan pada malam hari setelah shalat Maghrib, namun dimungkinkan juga pada waktu siang hari.

\section{Debus Produk Kebudaya-} an dan Agama

Sebelumnya di atas telah dibahas bahwa tarekat pernah berkembang di Banten sejak zaman Kesultanan Banten. Paling tidak pada masa Sultan Ageng Tirtayasa yang saat itu didampingi oleh Syaikh Yusuf al-Maqassari sebagai salah seorang tokoh su- 
fi, yang memulai karimya di Banten. Setidaknya Banten merupakan daerah yang terkenal dengan tingkat religiusitasnya yang tinggi dibandingkan dengan daerah-daerah lain di pulau Jawa.

Debus, sebagai salah satu bentuk kebudayaan di Banten, disebut-sebut sebagai bentuk dari ajaran tarekat. Syaikh debus tidak hanya seorang pemimpin dari suatu permainan ini, lebih dari itu dia adalah pemimpin tarekat di kampungnya. Keterkaitan ajaran debus dengan ajaran agama sangatlah erat, debus tidak dapat dilepaskan dari ajaranajaran agama, terutama praktik-praktik tarekat.

Debus yang berkembang saat ini di Banten berafiliasi dengan beberapa kelompok tarekat. Dari beberapa kelompok tarekat itu, mayoritas kelompok debus berafiliasi dengan Tarekat Rifa'iyah, karena tarekat inilah yang mengajarkan kekebalan bagi para pengikutnya.

Sementara kelompok debus Walantaka, Ciruas, dan Cikande berafiliasi dengan Tarekat Qadiriyah. Tarekat Qadiriyah yang berkembang

di Banten merupakan tarekat yang dibawa oleh Syaikh Abdul Karim Banten, yang saat itu memimpin Muslim Jawa di Mekkah.

Akulturasi debus dengan Islam merupakan bentuk sakralisasi kebudayaan, sehingga dikatakan bahwa hubungan debus dengan Islam seperti mata uang yang tidak memiliki arti jika salah satu bagiannya hilang.

Konsep ini dapat dipahami bahwa hanya Muslimlah yang dapat mempelajari permainan debus. Debus bukanlah semata-mata permainan pertunjukan kekebalan tubuh terhadap benda-benda tajam, namun lebih dari itu debus merupakan sikap kepasrahan, totalitas kepada Allah.

Ritual dalam kelompok debus sebenarnya dimulai ketika seorang pemain debus bergabung dalam kelompoknya. Beberapa ritual yang terlihat paling penting adalah amalan (bacaan-bacaan tertentu) dan puasa. Kedua bentuk ritual ini memiliki pengaruh yang sangat besar. Puasa merupakan latihan pengendalian diri menahan hawa nafsu. Puasa dalam ritual ini bukan 
seperti puasa Ramadhan yang lazim dilaksanakan. Sedangkan puasa dalam ritual ini merupakan upaya pengolahan batin dengan tetap mengingat Allah.

Sedangkan jumlah puasa yang dijalankan oleh seorang murid dapat dilakukan selama 3-7 hari bahkan ada yang sampai 40 hari, perbedaan kuantitas tersebut bergantung pada kelompok yang ia ikuti.

Sementara amalan merupakan kegiatan zikir. Zikir ini biasanya dengan mengulang beberapa kalimat atau ayat-ayat al-Qur'an. Bentuk zikir disesuaikan dengan kemampuan yang ingin diperoleh.

Bentuk zikir yang paling. pendek adalah membaca berulang tahmid ataupun takbir, sedangkan yang paling panjang adalah pembacaan ayat Kursi atau bebrapa zikir khusus yang dimiliki kelompok tertentu. Jumlahnya beragam, ada yang perlu dibaca tiga kali bahkan ada yang dibaca tiga kali. Ritual zikir ini biasanya dilakukan setelah shalat wajib atau tahajud.
Disamping itu juga ada amalan yang bukan dari ayatayat al-Qur'an tetapi menggunakan bahasa kuna, ada yang menggunakan bahasa Sunda dan bahasa Jawa.

Di samping ritual yang harus dilakukan sebelum kegiatan pertunjukan, simbol Islam yang digunakan adalah beberapa bacaan ketika pertunjukan berlangsung. Maka dapat dikatakan bahwa ada tiga unsur utama dalam permainan debus; keyakinan atau tahuid kepada Allah, keyakinan akan kemampuan syaikh, dan rasa percaya diri pemain.

Budaya dan agama dalam permainan debus melebur menjadi satu, budaya sebagai bentuk dari pemikiran manusia dan agama sebagai bentuk keyakinan melahirkan pola baru dalam kehidupan masyarakat.

Di sinilah terjadi proses akulturasi pada masyarakat Banten, antara budaya lokal dengan nili-nilai ajaran Islam. Sakralisasi kebudayaan dalam kasus debus merupakan perwrujudan terhadap pemahaman keagamaan yang terealisasi dalam bentuk tindakan 
keberagamaan, religiusitas mereka.

Pelarutan antara agama dan budaya tersebut sebenarnya merupakan perlindungan kebudayaan -atas ajaran agama, sehingga perilaku dan kebudayaanya terasa ada nuansa suci dan sakral.

MA Tihami menjelaskan bahwa sakralisasi kebudayaan masyarakat dan kulturisasi agama dalam masyarakat adalah penyebab ku-atnya Islam di daerah-daerah tertentu. ${ }^{16}$ Sakralisai kebudayaan dalam kasus debus merupakan peruujudan terhadap permasalahan pemahaman keagamaan yang terealisasi dalam bentuk tindakan keberagamaan, religiusitas mereka.

\section{Penutup}

Demikianlah sebuah pandangan kaleidoskop terhadap Islam dan budaya Banten yang unik dengan tradisi dan kulturnya jika dipandang dari aspek pola kehiduapan budaya dan tradisi di Indonesia.

Deskripsi tentang budaya, kultur, dan kepemimpinan masyarakat Banten yang berorientasi dalam lingkup, kekhasan budaya, kultur kepe- mimpinan, simbol, warisan tradisi, dan produk budaya lokal (debus), dan sinkretisasi agama dengan budaya setempat diharapkan mampu memberikan khazanah intelektual dan warisan bangsa ini. Bahwa begitu kayanya Indonesia akan warisan budaya leluhur yang harus di lestarikan bersama.

\section{Catatan Alchir:}

1. Adapun penduduk etnik terbesar yang mendiami wilayah ini adalah suku Sunda, sebagian besar mendiami wilayah Banten Selatan sedangkan wilayah Banten Utara didiami oleh suku Jawa yang bermigrasi dari wilayah $\mathrm{Ci}$ rebon, sedangkan bahasa Sunda yang digunakan oleh masyarakat Banten termasuk dalam bahasa Sunda Kuna,lihat Koentjaraningrat, Manusia dan Kebudayaan di Indonesia, Jakarta, Djambatan, Cet. Ke-24, 2004.

2. Titik Pudjiasih, Perang, Dagang, Persahabatan, Surat-surat Suttan Banten, Jakarta, Yayasan Obor Indonesia, 2007, h. 17-23.

3. Menurut pendapat Dhofier tentang pandangan hidup kiyai, ia mendefinisikan konsep kiyai sebagai elemen penting dari suatu pesantren sekaligus merupakan gelar. terhadap ulama dari kelompok Islam tradisional yang memiliki pesantren. Lihat $\mathrm{Za}$ makhsyari Dhofier, Tradisi Pesantren, Studi Tentang Panda- 
ngan Hidup Kiai, Jakarta, LP3ES, 1985.

4. Hal tersebut senada seperti yang diungkapkan oleh Turmudi, bahwasanya hubungan kiyai dengan masyarakatnya diikat dengan emosi keagamaan yang membuat kekuasaan sahnya semakin berpengaruh.Kharisma yang menyertai aksi-aksi kiyai pun, menjadikan hubungan tersebut penuh dengan emosi. Lihat En. dang Turmudi, Perselingkuhan Kiai dan Kekuasaan, Yogyakarta, LkiS, 2004.

5. Sartono Kartodirdjo, Pemberontakan Petani Banten 1888, Jakarta, Pustaka Jaya, 1984. Lihat pula, Michael C. Williams, Sickle and Crescent, The Communist Revolt of 1926 in Banten, Ohio University, Centre for International Studies, 1990.

6. MA Tihami, Kiai dan Jawara di Banten, Studi tentang Agama, Magi, dan Kepemimpinan di Desa Pesanggrahan Serang, Banten, Jakarta, Tesis Universitas Indonesia, 1992.

7. Sartono Kartodirdjo, op. cit., h. 83.

8. Salah satu yang menjadi menarik dalam masyarakat Banten adalah peranan para jawara se. bagai satuan pengamanan. Jika di daerah-daerah lain di Indonesia polisi dan TNI memiliki peranan signifikan dalam masalah pengamana hajatan akbar, pentas, pemilu, dan sebagainya, maka yang terjadi di Banten adalah para jawaralah yang mengambil alih pengamanan tersebut, seperti halnya ketika rapat sidang pemilihan gubernur Banten untuk pertamakali. Selain itu pola pemikiran mayarakat Banten yang lebih memercayai para jawara.

9. Konflik dapat terjadi ketika salah satu pihak benar-benar merasa puas dengan posisinya dan menganggap pihak lain mengancam posisinya tersebut. Kharisma dapat dikatan sebagai salah satu instrumen terciptanya konflik tersebut. Lihat Dean G. Pruitt, Jeffrey Z. Rubin, Sung Hee Kim, Social Conflict Escalation, Stalemate, and Setllement, USA, McGraw-Hill, 1994.

10.Diskusi Weber mengenai pengesahan kekuasaan dimulai dari sini, sosiolog politik Weber banyak menganalisis mengenai struktur sosial dan perubahan sosial, khususnya tentang masya. rakat tradisional yang menjadikan kharisma sebagai legitimasi. Lihat Wardi Bachtiar, Sosiologi Klasik dari Comte Hingga Parsons, Bandung, Rosdakarya, 2006, h. 280.

11. Hubungan emosional yang erat antara jawara memunculkan rasa solidaritas yang tinggi terhadap kelompok mereka, hal ini memunculkan asabiah ataupun fanatisme kesukuan sebagaimana yang dikemukakan oleh Ibn Khaldun dalam Muqaddimahnya tentang teori asabiah dalam kekuasaan. Lihat Ibn Khaldun, Mugaddimah Ibn Khaldun, Jakarta, Pustaka Firdaus, 1986, h. 156161.

12. Roderick Martin, Sosiologi Kekuasaan, Jakarta, Raja Grafindo Persada, 1993, h. 70-71.

13. Kelompok jawara yang berperan dalam bidang ekonomi ini sering disebut dengan kelompok jawara 
pasar yang dipimpin oleh $H$. Chasan Sohib, beliaulah tokoh pemimpin jawara Banten yang paling disegani dan memimpin organisasi PPPSBBI. Bahkan bukan hanya aspek ekonomi saja yang dikuasai melainkan juga aspek politik dan pemerintahan. Hal ini ditandai dengan menangnya Ratu Atut Chosyiah sebagai gubernur Banten pada Pilkada Banten tahun 2006, Atut Chosyiah sendiri adalah putri dari $\mathrm{H}$. Chasan Sohib, Dimyati Natakusumah sebagai bupati Pandeglang, dan baru-baru ini Andika Hazyrumi (putra Atut Chosyiah) terpilih sebagai anggota DPD Banten dalam Pemilu 2009 lalu. Mereka inilah yang dikenal sebagai dinasti jawara H.Chasan Sohib, nampak jelas di sana terdapat bargaining politik kelompok jawara pasar di Banten.

14. Vredenbregth memberi makna debus atau dabus sebagai permainan pertunjukan kekebalan terhadap senjata tajam atau api dengan cara membakar diri. Lihat Vredenbregth, Debus in West Java, dalam BKI, 1973, h. 302.

15. Vredenbregth, op. cit., h. 305309.

16.MA Tihami, Islam Banten : Telaah Historis dan Sosio Kultural, Makalah Dialog Hukama.

\section{Daftar Pustaka}

Bachtiar, Wardi. Sosiologi Klasik Dari Comte hingega Parson, Remaja Rosdakarya, Bandung, 2006.
Bruinessen, Martin Van, Tarekat Nagsyabandiyah di Indonesia, Bandung, Mizan, 1992.

Dhofier, Zamakhsyari, Tradisi Pesantren, Studi Tentang Pandangan Hidup Kiai, Jakarta, LP3ES, 1985.

Djajadiningrat, P.A.A. Hossein, Tinjauan Kritis Tentang Sejarah Banten Sumbangan Bagi Pengenalan Sifat-sifat Penulisan Sejarah Jawa, Jakarta, Djambatan, 1983.

Masaaki, Okamoto dan Rozaki, Abdur, Kelompok Kekerasan dan Bos Lokal di Era Reformasii, Yogyakarta, CSEAS IRE Press, 2006.

Kartodirdjo, Sartono, Pemberonta. kan Petani Banten 1888. Jakarta, Pustaka Jaya, 1984.

Khaldun, Ibn, Muqaddimah Ibn Khaldun, Jakarta, Pustaka Firdaus, 1986.

Koentjaraningrat. Manusia dan Kebudayaan di Indonesia, Jakarta, Djambatan, Cet. Ke24, 2004.

Mattin, Roderick, Sosiclogi Kekuasaan, Jakarta, Raja Grafindo Persada, 1993.

McGlynn, Frank and Artur Tuden (ed), Pendekatan Antropologi pada Perilaku Politik, Jakarta, UI Press, 2000.

Pruitt, G. Dean, Rubin, Z. Jeffry and Kim, Sung Hee, Social ConAict, Escalation, Stalemate, and Settlemen, United States of America, McGraw-Hill, Inc $-2^{\text {nd }}$ ed. 1994.

....., Teori Konfik Sosial, Yogyakarta, Pustaka Pelajar, 2004.

Pudjiasih, Titik, Perang, Dagang, Persahabatan, Surat-surat Sultan Banten, Jakarta, Ya- 
yasan Obor Indonesia, Jakarta, 2007.

Tihami, MA, Kiai dan Jawara di Banten, Studi tentang Agama, Magi, dan Kepemimpinan di desa Pesanggrahan Serang, Banten, Jakarta,Tesis Universitas Indonesia,1992. Islam Banten : Telaah Historis dan Sosio Kultural. Makalah Dialog Hukama.
Turmudi, Endang, Perselingkuhan Kiai dan Kekuasaan, Yogyakarta, LKIS, 2004.

Vredenbregth, Debus in West Java, dalam BKI, 1973.

Williams, C. Michael, Sickle and Crescent, The Communist Revolt of 1926 in Banten, Ohio University, Centre for International Studies, 1990. 